\title{
Aspek Sosial dalam Naskah Drama Lelakon Karya Adny Sri Wahyudi
}

\author{
Kasih Widowati ${ }^{* 1}$ \\ ${ }^{1,2}$ Program Studi Sastra Jawa, Fakultas Bahasa dan Seni, Universitas Negeri Semarang
}

\begin{tabular}{l} 
Info Artikel \\
\hline Article History: \\
Diajukan January 9, 2019 \\
Diterima June, 302019 \\
Terbit June, 302019
\end{tabular}

Kata kunci:

aspek sosial;

naskah drama

\begin{abstract}
Abstrak
Penelitian ini mengenai aspek sosial serta kehidupan masyarakat yang tercermin dalam naskah drama Lelakon karya Andy Sri Wahyudi. Pendekatan yang digunakan yaitu pendekatan sosiologi sastra, dengan prespektif teks sastra. Metode dalam penelitian ini menggunakan metode strukturalisme-semoitik dengan teknik hermeneutik. Data penelitian berupa unsur-unsur yang terdapat dalam naskah drama Lelakon karya Andy Sri Wahyudi. Hasil dari penelitian ini meliputi: 1) struktur pembangun yang terdiri dari penokohan, latar, alur dan dialog. 2) aspek sosial yang berupa aspek ekonomi dan aspek moral. 3) kehidupan maskyarakat seperti kemiskinan, pengangguran, kriminalitas, dan pelecehan tercermin dalam naskah drama Lelakon karya Andy Sri Wahyudi. Naskah drama Lelakon menjadi cerminan refleksi bagi kehidupan masyarakat pada jaman sekarang. Dalam menjalani hidup usaha dan optimisme harus dilakukan. Usaha apapun dilakukan agar tercapai kebutuhan hidup seperti yang tercermin dalam naskah drama Lelakon karya Andy Sri Wahyudi.
\end{abstract}

Published by UNNES. This is an open access

\section{PENDAHULUAN}

Naskah drama Lelakon merupakan salah satu naskah drama berbahasa Jawa yang terdapat dalam buku Mak, Ana Asu Mlebu Ngomah (MAAMN) karya Andy Sri Wahyudi yang diterbitkan oleh Garudhawaca di Yogyakarta pada tahun 2014. Dalam buku MAAMN, terdapat tiga naskah drama yaitu Lelakon; Mak Ana Asu Mlebu Ngomah; dan Ora Isa Mati. dari tiga naskah drama tersebut naskah drama Lelakon menceritakan kehidupan sosialyang lebih menonjol dan lebih tepat untuk diteliti dalam aspek sosial. Naskah drama Lelakon Menggu-

E-mail:kasihwidowati13@gmail.com

Alamat: Gedung B-8 Fakultas Bahasa dan Seni Universitas Negeri Semarang

Kampus Sekaran, Gunungpati, Semarang 50229 nakan bahasa Jawa, sebagai medium yang dipakai oleh orang - orang sekitar dia, dalam kehidupan sehari -hari yang ingin digambarkan di atas panggung. Dengan penggunaan bahasa Jawa ngoko, Andy menyampaikan cerita lokal dengan fokus utamanya terhadap kondisi sosial yang kacau untuk mewakili identitas komunitasnya. Naskah drama Lelakon merupakan salah satu cerita yang menceritakan keadaan sosial masyarakat masa sekarang. Dengan demikian masalah dalam penelitian ini adalah aspek sosial dan kehidupan yang tercermin dalam naskah drama Lelakon karya Andy Sri Wahyudi. Drama menurut Budianta (2002: 95) adalah sebuah karya genre sastra yang penampilanfisiknya memperlihatkan secara verbal adanya dialog atau cakapan di antara tokoh- tokoh yang ada. Drama dikelompokkan sebagai karya sastra karena media yang dipergunakan untuk menyampaikan gagasan atau pikiran pengarangnya adalah p-ISSN 2252-6463 e-ISSN 2686-5408 
bahasa.

Menurut Waluyo (2001: 6 - 30) stuktur drama terdiri dari struktur fisik dan batin, strukur fisik terdiri dari plot (alur), penokohan, dialog, dan latar (setting). Sedangkan struktur batin adalah tema dan amanat. Karakteristik drama terletak pada dialog. Hal ini sejalan dengan yang diungkapkan oleh Luxemburg (1984: 60) yang menyebutkan bahwa dialog-dialog dalam drama merupakan bagian terpenting dalam sebuah drama sebagai sarana primer di dalam drama, dialog dapat menentukan ingin seperti apa warna secara keseluruhan drama tersebut. Dialog dapat menuntun jalannya peristiwa sehingga dapat memberikan informasi yang seutuhnya tentang kejadian-kejadian yang ingin diketengahkan di dalam drama.

Drama sebagai mimetik terhadap kehidupan, berusaha memotret kehidupan secara riil. Sebagai masyarakat yang hidup berdampingan dan membutuhkan satu sama lain, aspek sosial akan selalu hadir dalam kehidupan bermasyarakat. Apalagi kehidupan di kampung yang masih sangat erat sosial antar warga dan lingkungannya. Aspek sosial sendiri merupakan suatu tindakan sosial yang digunakan untuk menghadapi masalah sosial. Masalah sosial timbul sebagai akibat dari hubungan dengan sesama manusia lainnya dan akibat tingkah lakunya. Masalah sosial ini tidaklah sama antara masyarakat yang sastu dengan masyarakat yang lain karena adanya perbedaan dalam tingkat perkembangan dan kebudayaannya, sifat kependudukannya, dan keadaan lingkungan alamnya (Soelaeman, 2009:5).

Aspek sosial menarik untuk dikaji karena aspek sosial menjelaskan tentang kehidupan dan masalah sosial yang terjadi di masyarakat yang dituangkan pengarang dalam karya sastranya. Aspek sosial terdiri atas beberapa aspek antara lain masalah sosial, moral, ekonomi, politik, dan agama. Naskah drama Lelakon menggambarkan masalah sosial yang dimiliki oleh masing- asing tokoh yang tercermin dalam kehidupan terutama masyarakat tempat tinggal pengarang. Aspek sosial yang akan diuraikan dalam penelitian ini antara lain sebagai berikut: aspek ekonomi dan aspek moral. Aspek kehidupan sosial dan cara/bentuk penyajian yang menampilkan kenyataan dalam masalah kehidupan sosial yang membuat peneliti berinisiatif untuk menganalisis lebih dalam naskah drama tersebut.

\section{METODE}

Penelitian ini berjudul aspek sosial dalam naskah drama Lelakon karya Andy Dri Wahyudi. Penelitian mengenai aspek sosial. Oleh karena itu, pendekatan yang dilakukan dalam penelitian ini dalah pendekatan sosiologi sastra. Pendekatan terhadap sastra yang mempertimbangkan segi-segi kemasyarakatan itu disebut sosiologi sastra, dengan menggunakan analisis teks untuk mengetahui strukturnya, untuk kemudian dipergunakan memahami lebih dalam lagi gejala sosial yang di luar sastra (Damono, 2002:3).

Wellek dan Warren membuat klasifikasi tiga jenis pendekatan yang berbeda dalam sosiologi sastra, yaitu sosiologi pengarang yang memasalahkan status sosial, ide- ologi sosial, dan lain- lain yang menyangkut pengarang sebagai penghasil sastra. kedua, sosiologi karya sastra yang memasalahkan karya sastra itu sendiri; yang menjadi pokok penelaahan adalah yang tersirat dalam karya sastra dan apa yang menjadi tujuannya. Yang ketiga, sosiologi sastra yang memasalahkan pembaca dan pengaruh sosial karya sastra (Damono, 1978:3). Dalam penelitian ini digunakan sosiologi yang mempermasalahkan karya sastra itu sendiri.

Data yang digunakan dalam penelitian ini adalah semua data yang berupa kata, frasa, kalimat, wacana yang terdapat dalam setiap dialog tokoh dalam naskah drama Lelakon karya Andy Sri Wahyudi. Data penunjang lain berupa buku-buku maupun artikel-artikel. Metode yang digunakan dalam penelitian ini adalah me tode strukturalisme-semiotik. Teknik pemerolehan data menggunakan teknik pembacaan heuristik. Dengan membaca dan mengamati setiap kalimat dan melakukan pemahaman teks. Setelah itu pengumpulan data yang berhubungan dengan rumusan masalah. Teknik analisis data menggunakan metode struktualisme-semiotika. Analisis data yang pertama dilakukan dengan menganalisis struktur pembangun naskah drama Lelakon. Struktur pembangun yang dianalisis yaitu tokoh, latar, alur dan dialog. Langkah berikutnya penganalisisan data yang berkaitan dengan aspek sosial, serta mengkaji aspek sosial yang terdapat dalam naskah drama Lelakon. Langkah selanjutnya mengkaji kehidupan masyarakat yang tercermin dalam naskah Lelakon karya Andy Sri Wahyudi.

\section{HASIL PEMBAHASAN}

Hasil analisis dan pembahasan akan diuraikan menjadi beberapa bagian yaitu (a.) struktur pembangun (b.) aspek sosial ,dan (c.) hubungan masyarakat yang terdapat dalam naskah drama Lelakon karya Andy Sri Wahyudi. Struktur pembangun naskah drama Lelakon karya Andy Sri Wahyudi, dibatasi hanya pada struktur fisik yaitu tokoh dan penokohan; latar; alur; dan dialog.

\section{Tokoh dan penokohan}

Tokoh yang terdapat dalam naskah drama Lelakon karya Andy Sri Wahyudi yaitu Cahyadi, Nanang Edan, Lik Kawit, Kajine Amat Sugih, Nursoleh, Nurdin, Jumiran Alap-Alap, Lestari, Samsinah, Siti, Cempluk dan Mbah Temu. Tokoh utama dalam naskah drama ini adalah Cahyadi dan lainnya menjadi tokoh tambahan. Penokohan adalah karakter watak tokoh yang terdapat dalam sebuah berita. Penokohan dalam naskah drama Lelakon karya Andy Sri Wahyudi antara lain.

1) Cahyadi: pemuda berumur 25 tahun, agak pecicilan, pantang menyerah dan tukang adu ayam

2) Nanang Edan: Lelaki muda berumur 27 tahun, dulu pembuat puisi, baik hati dengan Samsinah

3) Lik Kawit: duda berumur 45 tahun, memiliki satu anak. Bekas maling dan sok bijaksana dan mata keranjang.

4) Kajine Amat Sugih: tetua di kampung berumur 60 tahun, masih terlihat gagah, biasanya membawa tongkat agar terlihat berwibawa. Suka menyeramahi orang lain 
5) Nursoleh: pemuda umur 20 tahun, rajin solat dan lugu

6) Nurdin: lelaki muda umur 22 tahun, tukang adu ayam, setia. Gaya berpakaiannya model 70an dengan rambut kriwilan.

7) Jumiran Alap-Alap: maling kelas teri, berumur 21 tahun. Gaya berpakaian dan omongansepertiorang barat.

8) Lestari: perempuan umur 23 tahun, manis, anak kuliahanSamsinah: janda berumur 40 tahunan, memiliki 2 anak. Pekerja keras, agak galak dan baik hati

9) Siti: perempuan kelas 2 SMA berumur 17 tahun, penurut dan gemati dengan orang tua dan saudara, setia terhadapp pasangan.

10) Cempluk: janda anak satu berumur 24 tahun. murahn dan kegatelan dengan lelaki

11) Mbah Temu: kakek umur 75 tahun, namun masih sehat dan kuat. Hobinya memancing.

\section{Latar}

Latar adalah segala keterangan tenjuk, pengacuan yang berkaitan dengan waktu, ruang, dan suasana terjadinya peristiwa dalam suatu karya yang membangun cerita (Teeuw, 2003:44). Latar terbagi menjadi latar tempat, latar waktu dan latar suasana.

\section{Latar Tempat}

Latar tempat adalah tempat terjadinya cerita dalam drama. Latar tempat yang terdapat dalam naskah drama Lelakon antara lain didalam rumah, di depan rumah, dipinggir jalan, dan dipinggir sungai. Berikut contoh yang menunjukan latar tempat:

Ana ing dalan desa, Cahyadi numpak pit, singsotsingsot dhewe merga saking senenge, (diiringi lagu Sewu Kutha-ne Didi Kempot). Ing dalan, Cahyadi nyelip Jumiran Alap-Alap sing isih lari-lari, nyelip Siti karo Nurdin wing lagi gandhengan, banjur petukan Nursoleh sing mruput nggawa proposal kanggo mbangun mejid. (MAAMN, 2014:49)

Pada kutipan di atas terlihat bahwa Cahyadi sedang dalam suasana hati senang bersepeda di pinggir jalan desa. Menyapa semua orang yang lewat dengan senang sampai senyam senyum sendiri menengok kiri kanan tidak melihat jalan. Kutipan yang menandakan latar tempat adalah Ana ing dalan desa (berada di jalan desa).

\section{Latar Waktu}

Latar waktu menunjukan waktu kapan terjadinya peristiwa. Dalam naskah drama Lelakon karya Andy Sri Wahyudi terdapat latar waktu pagi hari, siang hari, sore hari, dan malam hari. Berikut contoh yang menunjukan latar waktu:

Lik Kawit Walah,Nang..., Nanang. Nom-noman bagus-bagus je edan! Kok isa ki iye ta ya? Hhmm... wis, lakonana uripmu, Nang..., nang. (ngunjal am-
began)Ealah..., idhep-idhep nggo tontonan esukesuk. (MAAMN,2014: 35)

Kutipan di atas, menggambarkan suasana pagi hari dengan Lik Kawit sedang bertemu dengan Nanang. Lik Kawit menyayangkan kehidupan Nanang yang sekarang menjadi orang gila. Lik Kawit menganggap kelakuan Nanang tersebut sebagai tontonan di pagi hari. Hal tersebut ditandai dengan kata tontonan esuk-esuk / tontonan di pagi hari.

\section{Latar Suasana}

Latar suasana merupakan lukisan kondisi keadaan saat peristiwa itu terjadi. Latar suasana pada naskah drama Lelakon karya Aandy Sri Wahyudi yaitu kaget, marah, senang, sedih, takut, dan khawatir. Berikut contoh yang menunjukan latar suasana.

Cahyadi Sing mbokwaske ki apa ta, Nang?! Nanang Edan kaget Nanang Edan wehladalah! Cahyadi ya kaget, mlupat ngadoh, pasang kuda-kuda kaya petinju. Siap-siap nek Nanang arep nyerang. (MAAMN, 2014: 52)

Berdasarkan kutipan di atas, terlihat jelas Cahyadi dan Nanang sama-sama terkejutnya. Cahyadi yang menanyai Nanang malah membuat kaget Nanang. Nanang yang terkejut pun membuat cahyadi juga terkejut.

\section{Alur}

Alur adalah rekayasa pencerita yang menandai sebuah fiksi, bukan peristiwa nyata. Alur yang terdapat pada naskah drama Lelakon karya Andy Sri Wahyudi adalah alur maju. Alur maju yaitu peristiwa-peristiwa tersusun secara kronologis, artinya peristiwa pertama diikuti peristiwa kedua, dan selanjutnya. Tahap pengenalan awal cerita naskah drama Lelakon menggambarkan keadaan saat semua tokoh berjalan berpapasan di depan rumah Lik Kawit. Para tokoh sibuk dengan kehidupan sendiri-sendiri.

Pada tahap pertikaian awal terjadi ketika Lik Kawit mengeluhkan kehidupan yang serba kurang dan harus memiliki uang dan kekuasaan jika ingin dihormati. Hal tersebut yang menimbulkan pertikaian antara Lik Kawit dan Cahyadi. Lik Kawit yang terus mengambil uang Cahyadi, membuat Cahyadi geram dan sudah tidak sabar. Tahap konflik terjadi ketika Cahyadi dan Lik Kawit bertengkar, dan membuat Lik Kawit harus pergi dari rumah. Tahap klimaks terjadi ketika Lik Kawit memberikan obat tidur kepada Lestari dan diketahui oleh Cahyadi. Cahyadi sudah marah besar dan mencari Lik Kawit. Tahap penyelesaian pada naskah drama Lelakon terjadi ketika Cahyadi pulang kerumah setelah mencari Lik Kawit dan Lestari menjerit menuduhnya memperkosa Lestari. Cahyadisudah tidaksabarlagi, dan bersumpah akan membunuh Lik Kawit jika nanti bertemu.

\section{Dialog}

Dialog dalam drama berfungsi untuk pengarang menyampaikan informasi, menjelaskan fakta atau ide- 
ide utamanya. Penulis menggunakan ragam lisan untuk menuliskan dialog. Ragam lisan yang dimaksud adalah ragam lisan yang komunikatif dan bukan ragam tulis. Ragam lisan terdapat dalam naskah drama Lelakon karya Andy Sri Wahyudi seperti kutipanberikut.

Nursoleh Iki, dikon Kajine Amat ngubengke proposal nggo ngapikke mejid. Cahyadi Wooo! Hla iya! Dhilit engkas aku ki ya arep sregep salat nang mejid je! Rak ya aku melu bangga ta nek mejide apik-resik?! Marakke sing salat khusyuk. Nursoleh Hla iya. Sing adu jago leren. Ya, sik ya, Cah. Tak luhurandhisik!'Assalamualaikum.

(MAAMN, 2014: 78)

Pada dialog tersebut, ragam bahasa lisan yang digunakan cenderung lebih bebas dan kalimatnya lebih efektif. Dialog dalam naskah juga dapat mermpertegas watak tokoh dalam cerita. Bahasa jawa yang digunakan oleh para tokoh dalam naskah drama ini adalah bahasa Jawa ngoko. Bahasa Jawa ngoko umum digunakan oleh masyarakat Jawa dengan tingkat status sosial yang sama. Seperti antara tetangga, teman dan saudara.

\section{Aspek sosial}

Aspek sosial yang akan dibahas dalam penelitian ini adalah aspek ekonomi dan aspek moral. Aspek ekonomi yang terdapat dalam naskah drama Lelakon karya Andy Sri Wahyudi adalah masalah kemiskinan dan pengangguran. masalah kemiskinan menjadi salah satu masalah yang disorot oleh pengarang. Seperti yang dirasakan oleh tokoh Samsinah yang tidak bisa membawa anaknya yang sakit periksa ke dokter. Berikut kutipannya:

Yu Samsinah arep mlaku mlebu ngomah. Siti usul saran. Siti Digawa nyang dokteran wae, Mbok. Samsinah noleh rada jengkel. Samsinah Dhuwite mbahne pa?!(MAAMN, 2014: 66).

Diaolog tersebut memperlihatkan masalah kemiskinan yang diderita oleh Samsinah. Untuk membawa anaknya kedokter tidak bisa karena tidak ada uang. Hanya bisa merawatnya di rumah. Kemiskinan yang terjadi bukan karena kurangnya usaha, namun karena keadaan yang belum memihak. Selain kemiskinan, masalah pengangguran juga terdapat dalam naskah drama Lelakon. Haltersebut yang terjadi pada para tokoh, yang tidak memiliki pekerjaan. Seperti Cahyadi dan Nurdin, mengandalkan adu ayam untuk menncukupi kebutuhan sehari-hari.

Samsinah Wegah! Kowe kuwi, Cah, ra isin ro pitikmu pa? Kudune sing obah nyambut gawe ki rak kowe ta? Malah sing nyambut gawe pitikmu. Lagi nde dhit sithik we ndhangak! Arep mboking aku barang. Cahyadi Ha... nganu je, Yu. Ha, nganu e... Kahanan. (MAAMN, 2014: 80)

Berdasarkan kutipan di atas, Cahyadi mengadu ayam karena keadaan yang dirasakan. Banyaknya pen- gangguran karena kurangnya lowongan pekerjaan dan kurangnya pengalaman dan keterampilan yang dimiliki.

\section{Aspek Moral}

Moral merupakan ajaran tentang baik buruk yang dierima masyarakat mengenai perbuatan, sikap, kewajiban dan sebagainya. Menurut Soeroso (2006:3) moral menjadi tolak ukur untuk menganggap perilaku seseorang, bertentangan dengan hati nurani atau tidak. Aspek moral dalam naskah drama Lelakon karya Andy Sri Wahyudi dibagi menjadi dua yaitu moral baik dan moral tidak baik. Moral baik terdiri dari rasa pantang menyerah, pekerja keras, kesabaran, optimis dan tolong menolong. Berikut contoh yang terdapat dalam naskah drama Lelakon.

Cahyadi Ha... nganu je, Yu. Ha, nganu e... Kahanan. Samsinah Aku ki yakahanan, Cah! Tur rak ya kudu nganggo kringet ta? (MAAMN, 2014: 80)

Dialog tersebut menggambarkan Samsinah merupakan orang yang berusaha dan bekerja keras dengan tenaga dan keringatnya sendiri untuk menghidupi keluarganya. Moral tidak baik yang terdapat dalam naskah drama ini antara lain meliputi tidak memiliki sopan santun, perjudian, menjual diri, pelecahan, tidak bertanggung jawab, dan mencuri. Berikut kutipan salah satu contoh moral tidak baik.

Jumiran Alap-alap muncul maneh, madik-madik, namatake kiwa tengen, banjur njupuk kumbahane Yu Samsinah. Nanging apes, Jumiran konangan sing maling, banjur dioyak-oyak wong akeh (MAAMN, 2014: 72)

Berdasarkan kutipan di atas, Jumiran yang sedang maling ketahuan oleh warga. Karena kehidupan yang semakin menekan orang, membuat orang akan mencari segala cara untuk bertahan hidup. Hal yang mudah dan praktis menjadi salah satu pikiran untuk mampu bertahan hidup. Namun, hal yang praktis itu diluapkan dengan cara yang tidak baik. Seperti yang dilakukan oleh Jumiran Alap-Alap.

\section{Cermin Kehidupan dalam Naskah}

Naskah drama Lelakon karya Andy Sri Wahyudi menggambarkan keadaan sosial masyarakat yang terdapat pada lingkungannya pada masa kecil. Andy menceritakan dan memprotes kehidupan sosial yang terjadi dilingkungannya. Masalah yang digambarkan Andy dalam naskah Lelakon terjadi dari dulu sampai sekarang. Masalah tersebut tentang kemiskinan dan moralitas masyarakat pada zaman sekarang. Banyak warga Indonesia yang masih tergolong miskin. Dari data BPS (Novelino, 2019) tercatat pada tahun 2019 masih ada 25,14 juta warga Indonesia yang tergolong miskin. Angka tersebut menurun daripada tahun sebelumnya. Kemiskinan digambarkan oleh sebagian besar tokoh dalam naskah drama Lelakon. Kemiskinan yang terjadi dapat ditekan menurun dengan cara mengajak para warga untuk men- 
gasah keterampilan dan kemampuannya.

Didirikan UMKM untuk para warga yang ingin mendirikan usaha namun tidak memiliki modal. Para warga diberikan pelatihan cara berusaha dan cara mengolah modal dan keuangan yang benar. Meskipun masyarakat yang tergolong miskin masih terlalu banyak cara tersebut dapat mengurangi sedikit beban yang dirasakan masyarakat miskin. Selain kemiskinan, penurunan masyarakat juga terdapat dalam kasus pengangguran. Seperti tokoh para lelaki yang digambarkan pengarang dalam naskah drama Lelakon. Kasus pengangguran di Indonesia menurun menjadi 6,82 juta orang. (Makki, 2019). Masih banyak para pengangguran di Indonesia. Adanya ijasah sekolah ataupun kuliah tidak akan bisa digunakan apabila tidak adanya kreativitas dan pengalaman kerja. Serta tidak adanya lowongan pekerjaan yang mendukung. Ada baiknya jika para anak muda diberikan atau diajarkan keterampilan sehingga bisa membuka lapangan pekerjaan sendiri dan tidak mencari pekerjaan. Kriminalitas yang ada di Indonesia semakin meningkat dibandingkan kemiskinan dan pengangguran yang menurun. Hal tersebut dikarenakan kurangnya pengalaman dalam bekerja dan pendidikan yang membuat orang akan melakukan berbagai cara untuk memenuhi kebutuhannya. Kriminalitas di Indonesia yang terbanyak adalah kasus pencurian. Hal tersebut juga digambarkan dalam naskah drama Lelakon yang terjadi pada Jumiran dan suami

Cempluk. Pelecehan juga menjadi cerminan kehidupan yang terdapat dalam naskah drama Lelakon digambarkan oleh tokoh Lestari yang dilecehkan Lik Kawit. Pelecehan di Indonesia meningkat. Tindakan seperti pemerkosaan, banyak terjadi di jaman sekarang. Pada tahun 2019 terdapat kasus pelecehan terhadap wanita yaitu sejumlah 406.178 kasus (Ruri, 2019). Tindak pelecehan dapat dihindari apabila selalu waspada dan berjaga- jaga. Memakai baju yang sopan dan tertutup, berperilaku yang sopan, berjalan bersama dengan teman atau berada ditempat yang ramai, menguasai bela diri dasar untuk berjaga-jaga, dan lainnya dapat meminimalisir terjadinya tindak pelecehan terhadap perempuan.

\section{SIMPULAN}

Hasil penelitian ini menunjukan naskah drama Lelakon karya Andy Sri Wahyudi merupakan karya sastra yang termasuk pada jenis drama realisme, karena menceritakan kehidupan nyata pada masyarakat yang diperkuat pada latar melalui aspek sosial yang terdiri dari dari aspek ekonomi yang berupa masalah kemiskinan dan pengangguran serta aspek moral buruk yang menjadi dominan pada naskah drama Lelakon. Kehidupan masyarakat pada masa sekarang seperti halnya kemiskinan, pengangguran, kriminalitas dan pelecehan menjadi kondisi sosial yang dituangkan pada naskah drama Lelakon karya Andy Sri Wahyudi.

\section{DAFTAR PUSTAKA}

Budianta, Melani, dkk. 2002. Membaca Sastra (Pengantar Memahami Sastra untuk Perguruan Tinggi). Magelang: Indonesia Tera

Damono, Sapardi Djoko. 1978. Sosiologi Sastra: Sebuah Pengantar Ringkas. Jakarta: Pusat Pembinaan dan Pengembangan Bahasa

Damono, Sapardi Djoko. 2002. Pedoman Penelitian Sastra. Jakarta: Pustaka Bahasa

Endraswara, Suwardi. 2003. Metodologi Penelitian Sastra. Yogyakarta: Pustaka Widyatama

Luxemburg, Jan Van, dkk. 1984. Pengantar Ilmu Sastra. Jakarta: Gramedia

Makki, Safir. 2019. Jumlah Pengangguran Februari 2019 Turun Jadi 6,82 Juta Orang. CNNIndonesia. https://m.cnnindonesia.com/ekonomi/20190506124326-532-392272/ jumlah-pengangguran-februari-2019-turun-jadi-682-juta-orang. Diakses 20 Juli 2019

Novelino, Andry. 2019. Jumlah Penduduk Miskin RI Maret 2019 TurunJadi25, 14Juta.CNNIndonesia.https://m.cnnindonesia.com/ekonomi/20190715132823-532-412205/ jumlah-penduduk-miskin-ri-maret-2019-turun-jadi2514-juta di akses 20 Juli 2019

Ruri, Iqraa. 2019. Catatan Tahunan 2019 Komnas Perempuan : Kasus Kekerasan Terhadap Perempuan Meningkat. Jurnal Perempuan. https://www.jurnalperempuan. org/warta-feminis/catatan-tahunan-2019-komnasperempuan-kasus-kekerasan-terhadap-perempuanmeningkat di akses 20 Juli 2019 di akses 20 Juli 2019

Soelaeman, M. Munandar. 2009. Ilmu Sosial Dasar. Bandung: Refika Aditama 